\title{
Photoluminescence and X-ray photoelectron spectroscopic study of milled-ZnO material prepared by high energy ball milling technique
}

\author{
Wanichaya Mekprasart ${ }^{\mathrm{a}}$, Balaji R. Ravuri ${ }^{\mathrm{b}}$, Rattikorn Yimnirun ${ }^{\mathrm{c}}$, Wisanu Pecharapa ${ }^{\mathrm{a}, *}$ \\ a College of Nanotechnology, King Mongkut's Institute of Technology Ladkrabang, Bangkok, Thailand \\ b Gandhi Institute of Technology and Management, Hyderabad, Telangana 502329 India \\ c School of Energy Science and Engineering, Vidyasirimedhi Institute of Science and Technology, Rayong \\ 21210 Thailand
}

*Corresponding author, e-mail: wisanu.pe@kmitl.ac.th

Received 16 Oct 2019

Accepted 20 Mar 2020

\begin{abstract}
Luminescence properties that are correlated to near band edge emission and defect-related emission of milled zinc oxide $(\mathrm{ZnO})$ powder prepared by high energy ball milling technique are investigated. Commercial $\mathrm{ZnO}$ powder (particle size of $525 \mathrm{~nm}$ ) was chosen as starting material in milling process to produce ultrafine ZnO powder. The milling process was carried out at different speeds; 0, 200, 400 and $600 \mathrm{rpm}$ for $10 \mathrm{~min}$. After milling at high speed, change in color of milled $\mathrm{ZnO}$ powder was clearly observed that could be due to the defects in $\mathrm{ZnO}$ structure induced by mechanical strain during milling process. Surface morphology of milled ZnO powder was monitored by field-emission scanning electron microscopy (FESEM). Element component and surface chemical states of the samples were analyzed by X-ray photoelectron spectroscopy (XPS). Optical property of milled samples was investigated by diffuse reflectance UV-Vis spectrometer. Meanwhile, room-temperature photoluminescence spectroscopy of the milled samples was performed. The milled ZnO particle size was distinctly decreased to ca. $200 \mathrm{~nm}$ affirmed by FESEM images. Photoluminescence (PL) spectra of milled ZnO sample showed two prominent emission bands; UV and visible region. Visible emission intensity increased with increasing milling speed that would be attributed to greater structural defects caused by high mechanical strain during milling process.
\end{abstract}

KEYWORDS: photoluminescence, X-ray photoelectron spectroscopy, milling, ZnO

\section{INTRODUCTION}

Zinc oxide $(\mathrm{ZnO})$ based material is greatly attractive as an effective semiconductor owing to its remarkable properties including direct wide band gap energy (3.37 eV), large exciton binding energy (60 meV), high electron mobility and good stabilities at high thermal and chemical environment [ 1 , 2 ]. Regarding promising properties of $\mathrm{ZnO}$ nanostructures, various demanding utilizations are based on this material such as antibacterial material, photodetector, photocatalyst, light emitting diode, solar cell and optical waveguide [3-7]. Thus, the production of ultrafine $\mathrm{ZnO}$ powder in nanoscale has been focused and different synthesis methods have been proposed via both bottom-up and top-down processes. For bottom-up processes, final product of $\mathrm{ZnO}$ particles in different sizes and geometries can be obtained via chemical route using zinc precursor with reducing agents, depending on proper precursor ratio, temperature and pressure. Different methods for the preparation of $\mathrm{ZnO}$ nanoparticles have been conducted including homogenous precipitation, spray pyrolysis, sol-gel network and hydrothermal method [8-11]. However, ZnO powder in commercial product is in the stable powder as oxide powder that is difficult to produce in nanosize structure. Therefore, top-down process such as mechanical milling process is an alternative route to reduce particle size and obtain amorphous or nanostructured material and meet the requirement of large-scale production. High energy ball milling process is one of effective technique in mechanical process for particle size reduction and deformed structure by impact force mechanism. The impact energy during this process provides greater effect on milled materials than conventional milling process resulting in further particle size reduction in shorter process time. During the milling process, particle fracture can be created by the collision among par- 
ticles, balls and container wall leading to significant size reduction [12]. Meanwhile, the strain in the lattice and smaller pieces in the crystal occurring in this reaction can lead to the defects in its structure, for example, vacancies, dislocations, stacking faults and grain boundaries [13]. The effects of several parameters under milling process must be investigated such as operation time, milling speed, temperature, diameter and number of balls, container volume, and the mass ratio between balls and precursor weight [14]. Milling speed is considered to be a crucial parameter in milling process. It was reported that the particle size of alumina and magnesia mixture in high energy milling process was decreased gradually from 42.92 to $9.00 \mu \mathrm{m}$ under different milling speeds from 60-240 rpm within $3 \mathrm{~h}$ [15]. Meanwhile, color changing from white to yellow in $\mathrm{ZnO}$ powder can be occurred after milling at high speed. This result can be originated from thermal energy during milling operation leading to metallothermic reduction or compound formation and relevant structural defects. Therefore, further study in type of defects playing key role in color changing of $\mathrm{ZnO}$ powder is necessary.

In this work, size reduction of $\mathrm{ZnO}$ powder was carried out by mechanical high-energy ball milling method. The products of as-received and milled $\mathrm{ZnO}$ powder were characterized by mean of surface morphology, crystalline structure and particle size. Meanwhile, the defect and oxidation state of $\mathrm{ZnO}$ powder after milling process was deeply investigated by photoluminescence spectra and X-ray photoelectron spectroscopy technique to identify its origin in yellow appearance.

\section{MATERIALS AND METHODS}

Commercial zinc oxide (ZnO) powder (Ajax Finechem Pty Ltd, Australia) with average particle size of $500 \mathrm{~nm}$ was used as starting material in high energy ball milling process. The as-received $\mathrm{ZnO}$ powder with powder to zirconia ball $(\phi=1 \mathrm{~mm}$, (Tosoh, Japan)) weight ratio of 1:30 was loaded in zirconia container. The milling speed was varied 200, 400 and $600 \mathrm{rpm}$ for $10 \mathrm{~min}$ under ambient air atmosphere at room temperature. After that, $\mathrm{ZnO}$ power was separated from the balls by sifting and baked at $100{ }^{\circ} \mathrm{C}$ for $2 \mathrm{~h}$ to remove moisturizer in the sample. The relevant properties of $\mathrm{ZnO}$ ultrafine powders after milling were investigated by various techniques. Crystalline structure and phase identification were characterized by X-ray diffractometer (XRD; Rigaku Smartlab) with $\mathrm{Cu}$ $\mathrm{K}_{\alpha}(\lambda=0.154 \mathrm{~nm})$. Morphologies of before-/after-

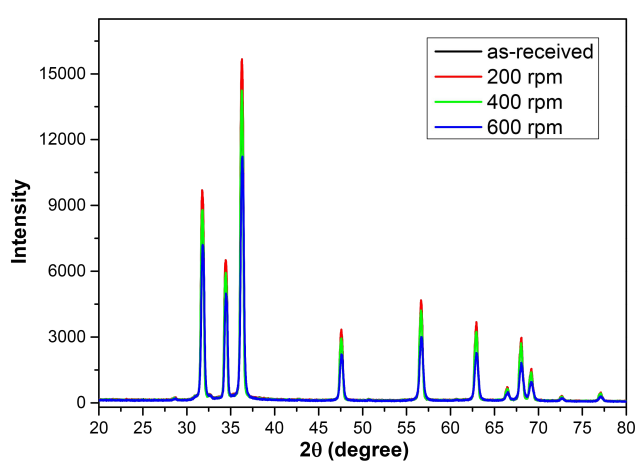

Fig. 1 XRD patterns of as-received $\mathrm{ZnO}$ powder (black line, overlaid with red line), and milled-ZnO at $200 \mathrm{rpm}$ (red line), $400 \mathrm{rpm}$ (green line) and $600 \mathrm{rpm}$ (blue line).

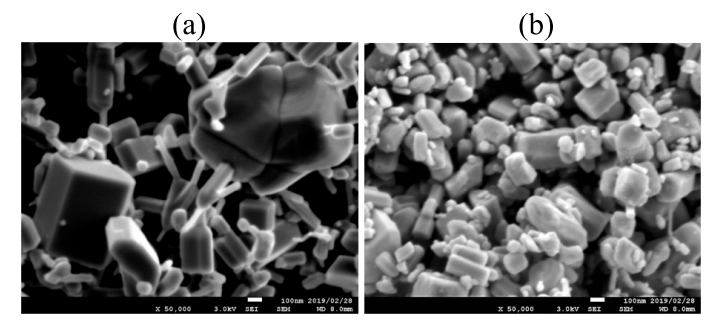

Fig. 2 FESEM images $(\times 50000)$ of (a) as-received $\mathrm{ZnO}$ and (b) milled-ZnO at $600 \mathrm{rpm}$ for $10 \mathrm{~min}$.

milled products were monitored by field-emission scanning electron microscopy (FESEM; JEOL JSM7001F). Chemical element and oxidation state on ZnO surface were observed by X-ray photoelectron spectroscopy (XPS) at beamline 5.2, Synchrotron Light Research Institute, Thailand. Meanwhile, crystalline defect of $\mathrm{ZnO}$ structure was analyzed by PL spectroscopy performed at room temperature using He-Cd laser with specific wavelength at $325 \mathrm{~nm}$ and diffuse reflectance spectroscopy technique.

\section{RESULTS}

Fig. 1 illustrates XRD patterns of as-received $\mathrm{ZnO}$ powder and $\mathrm{ZnO}$ powders milled at different speeds of 200, 400, and $600 \mathrm{rpm}$. The characteristic peaks situated at $2 \theta$ of $31.3^{\circ}, 34.4^{\circ}, 36.9^{\circ}, 47.7^{\circ}$, $56.5^{\circ}$ are associated to (100), (002), (101), (102) and (110) hexagonal wurtzite zinc oxide planes, respectively (JCPDS No. 36-1451). It is noticeable that the characteristic XRD peaks become broaden and their intensities drop significantly as the milling speed was beyond $400 \mathrm{rpm}$, implying reduction in their crystallite size. Their corresponding crystallite size was also calculated using well-known Scher- 


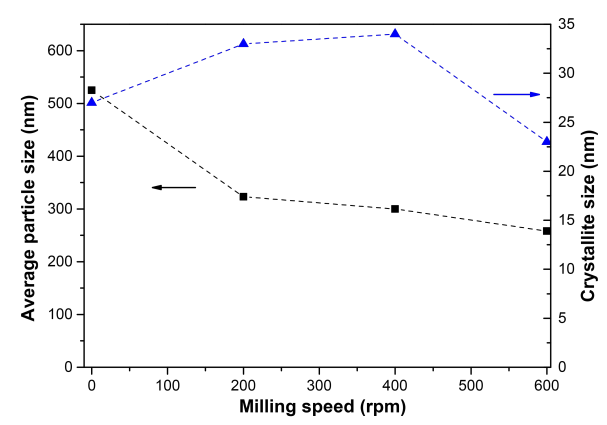

Fig. 3 Average particle size ( $\boldsymbol{\square})$ and calculated crystallite size $(\boldsymbol{\Delta})$ of as-received $\mathrm{ZnO}(0 \mathrm{rpm})$ and milled-ZnO at speeds of 200, 400 and $600 \mathrm{rpm}$.

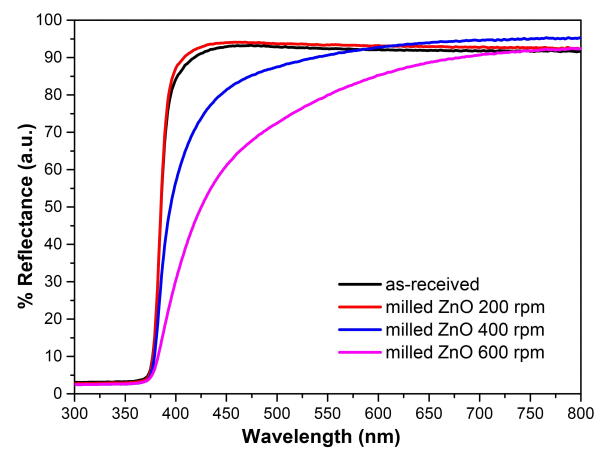

Fig. 4 Diffuse reflectance spectra of as-received $\mathrm{ZnO}$ and milled-ZnO at speeds of 200, 400 and $600 \mathrm{rpm}$.

rer's equation as illustrated in Fig. 3. The particle size values measured by particle size analyser and FESEM images are shown in Fig. 2. As observed in Fig. 2(a) and Fig. 2(b), significant reduction in its size was achieved after milling process. The average particle size of the powder was reduced considerably from $\sim 530 \mathrm{~nm}$ for as-received sample to $\sim 240 \mathrm{~nm}$ for $\mathrm{ZnO}$ sample milled at $600 \mathrm{rpm}$. In milling process, the increase in crystallite size at milling speed of $200 \mathrm{rpm}$ and $400 \mathrm{rpm}$ could be originated from the shear force between material and balls occurring at low milling speed that can lead to the agglomeration of $\mathrm{ZnO}$ particles and also the increase in crystallite size. Meanwhile, greater impact force during milling at higher milling speed beyond this certain speed could lead to crystal distortion and reduction in crystallite size.

Fig. 4 reveals the UV-Vis diffuse reflectance spectra of all samples. It is noticed that the reflectance in UV region ( $\lambda=300-375 \mathrm{~nm})$ of all samples is less than $5 \%$, suggesting high UV absorptivity of the samples. The sharp reflectance edge can be

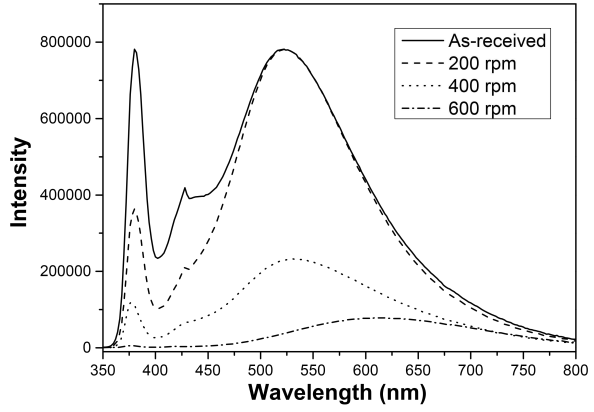

Fig. 5 Photoluminescence of: as-received $\mathrm{ZnO}$ and milled-ZnO at speeds of 200, 400 and $600 \mathrm{rpm}$ for $10 \mathrm{~min}$.

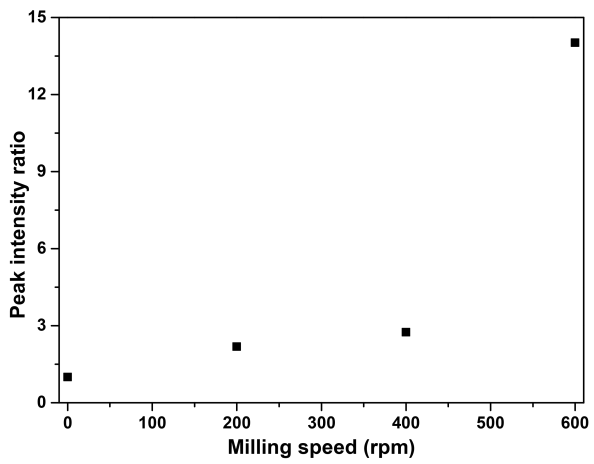

Fig. $6 I_{\mathrm{VIS}} / I_{\mathrm{NBE}}$ peak intensity ratio of as-received $\mathrm{ZnO}$ and milled-ZnO at speeds of 200, 400 and $600 \mathrm{rpm}$ for $10 \mathrm{~min}$.

observed for all samples at $\lambda \sim 375 \mathrm{~nm}$ due to typical band gap of $\mathrm{ZnO}$. Light with lower photon energy than its optical band gap is unable to be absorbed and photon-induced electron-hole pair is not generated, leading to high reflectivity of light in visible region. Moreover, it is obvious that the reflectance intensities of milled $\mathrm{ZnO}$ powders in visible region $(\lambda=400-600 \mathrm{~nm})$ drops significantly with increasing milling speed, suggesting the enhancement in visible absorptivity of the milled samples. The color of the sample consequently changes from white for as-received $\mathrm{ZnO}$ to pale yellow appearance for the sample milled at $600 \mathrm{rpm}$ (pictures are not shown). This feature could relate to the optical absorption of structural defect levels within $\mathrm{ZnO}$ band gap. Therefore, this result implies the creation of structural defects of the samples induced by mechanical milling process.

As seen in Fig. 5, PL spectra of as-received $\mathrm{ZnO}$ sample possesses prominent narrow peak positioned at about $375 \mathrm{~nm}$ that is corresponded to typical near-band-edge (NBE) emission of $\mathrm{ZnO}$ related to 


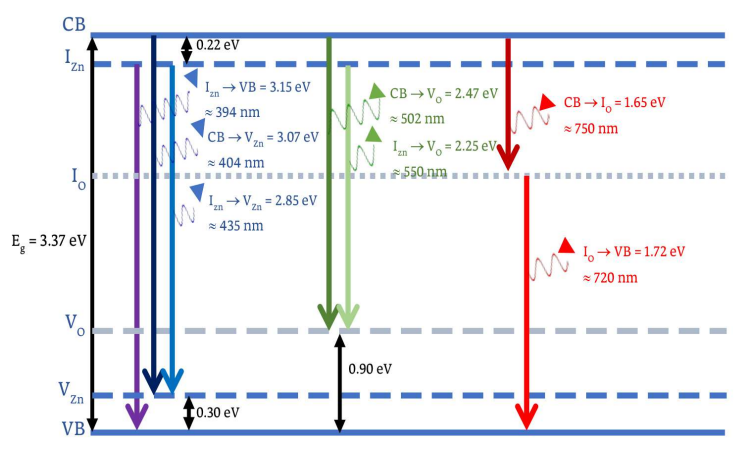

Fig. 7 Energy levels of structural defects in $\mathrm{ZnO}$ and corresponding transition pathways responsible for its photoluminescence.

its typical band gap of $3.37 \mathrm{eV}$ and is also in harmony with the reflectance spectra in Fig. 4 [16]. Moreover, there is an observable shoulder blue luminescence spectrum nearby NBE emission at around $420 \mathrm{~nm}$ in all samples which is related to the emission of zinc interstitial and zinc vacancy defect [17]. The broad emission covering the wavelength of 450-700 nm typically attributed to relevant defects including oxygen vacancy $\left(\lambda_{\text {peak }} \sim 550 \mathrm{~nm}\right)$ and oxygen interstitial $\left(\lambda_{\text {peak }} \sim 600 \mathrm{~nm}\right)$ whose peak is positioned at around $550 \mathrm{~nm}$ can be observed in all samples. This emission spectrum indicates the defects from oxygen vacancy which leads to the appearance of broad yellow emission relating to oxygen interstitial defect [18]. It is obvious that the intensities of both NBE and visible emission band decrease significantly as the milling speed increases. The peak intensity ratios of visible broad emission to near-band-edge emission $\left(I_{\mathrm{VIS}} / I_{\mathrm{NBE}}\right)$ of all samples indicating the qualitative and quantitative existence of defect-related emission compared to NBE emission are represented in Fig. 6 . The $I_{\mathrm{VIS}} / I_{\mathrm{NBE}}$ ratio is increased considerably as the milling speed increases. The intensity ratio of as-received $\mathrm{ZnO}$ is found to be about 1 and this ratio increases drastically to be 14 as the milling speed increases to $600 \mathrm{rpm}$. This phenomenon suggests that these structural defects could be increased by greater mechanical stress provided by milling process with higher speed. The PL spectra of all samples are accompanied with weak near infrared band peaked at $760 \mathrm{~nm}$ that is typically related to lattice disorder or defect along c-axis of $\mathrm{ZnO}$ [17].

\section{DISCUSSION}

According to PL results, schematic picture of energy level positions that take responsibility of NBE and visible emission is proposed as depicted in Fig. 7. There are various transition pathways of emission. Under laser excitation with photon energy greater than optical bandgap of $\mathrm{ZnO}(>3.37 \mathrm{eV})$, electrons are excited to conduction band leaving holes in valence band. After few nanoseconds, electrons will recombine with holes and emit corresponding photon by different transition pathways. The NBE emission is from the recombination of electrons at the bottom of conduction band and holes at the uppermost of valence band $(\mathrm{CB} \rightarrow \mathrm{VB})$. Many structural defect levels including zinc interstitial $\left(\mathrm{I}_{\mathrm{Zn}}\right)$, oxygen interstitial $\left(\mathrm{I}_{\mathrm{O}}\right)$, zinc vacancy $\left(\mathrm{V}_{\mathrm{Zn}}\right)$ and oxygen vacancy $\left(\mathrm{V}_{\mathrm{O}}\right)$ can be created during ball milling process. $\mathrm{I}_{\mathrm{Zn}}$ and $\mathrm{I}_{\mathrm{O}}$ are located at $0.22 \mathrm{eV}$ and $1.65 \mathrm{eV}$ below conduction band [19-21]. While $\mathrm{V}_{\mathrm{Zn}}$ and $\mathrm{V}_{\mathrm{O}}$ are typically situated at $0.30 \mathrm{eV}$ and $0.90 \mathrm{eV}$ over valence band [22,23]. It is possible for excited electrons either from conduction band or captured electrons at $\mathrm{ZnO}$ to recombine with holes in valence band or captured holes at $\mathrm{V}_{\mathrm{Zn}}$ to release blue emission with corresponding wavelengths of $394 \mathrm{~nm}\left(\mathrm{I}_{\mathrm{Zn}} \rightarrow \mathrm{VB}\right), 405 \mathrm{~nm}\left(\mathrm{CB} \rightarrow \mathrm{V}_{\mathrm{Zn}}\right)$ and $435 \mathrm{~nm}\left(\mathrm{I}_{\mathrm{Zn}} \rightarrow \mathrm{V}_{\mathrm{Zn}}\right),(\lambda=400-450 \mathrm{~nm})$. This emission band is clearly observed as a shoulder band nearby NBE. Furthermore, prominent broad green-yellow emission in PL spectra with increasing $I_{\mathrm{VIS}} / I_{\mathrm{NBE}}$ for the milled samples is attributed to the emission from $\mathrm{CB} \rightarrow \mathrm{V}_{\mathrm{O}}(\lambda \sim 500 \mathrm{~nm})$ and $\mathrm{I}_{\mathrm{Zn}} \rightarrow \mathrm{V}_{\mathrm{O}}(\lambda \sim 550 \mathrm{~nm})$. Meanwhile, the red-near infrared emission $(\lambda=600-750 \mathrm{~nm})$ could be originated from the $\mathrm{CB} \rightarrow \mathrm{I}_{\mathrm{O}}(\lambda \sim 750 \mathrm{~nm})$ and $\mathrm{I}_{\mathrm{O}} \rightarrow \mathrm{VB}$ $(\lambda \sim 720 \mathrm{~nm})$ transition. In addition, there is significant red-shift of visible emission band to higher wavelength as the milling speed increases to $600 \mathrm{rpm}$. The behavior suggests that the greater mechanical impact can induce the shift in defect level of $V_{O}$ and $I_{O}$, that is responsible for the shift of visible emission of milled $\mathrm{ZnO}$.

XPS measurement of as-received $\mathrm{ZnO}$ and $\mathrm{ZnO}$ milled at $600 \mathrm{rpm}$ was carried out to further investigate the chemical states in both samples. As shown in Fig. 8(a), the $\mathrm{Zn} 2 p_{3 / 2}$ peak positioned at $1021.4 \mathrm{eV}$ with spin orbit splitting around $23 \mathrm{eV}$ is a characteristic for divalence $\mathrm{Zn}^{2+}$ of $\mathrm{Zn}-\mathrm{O}$ bond in $\mathrm{ZnO}$ lattice. Slight shift to higher binding energy than typical $\mathrm{Zn}$ in perfect lattice could contribute to $\mathrm{Zn}-\mathrm{O}_{\text {vacancy }}$ bonds in the inner surface without change in surface $\mathrm{Zn}$ state induced by milling process. It is implied that such defects should occur in the lattice rather than its surface [24]. In Fig. 8(b), O1s peak of oxygen in wurtzite $\mathrm{ZnO}$ lattice should typically be at around 529.8-529.9 eV [24-27]. 
(a)
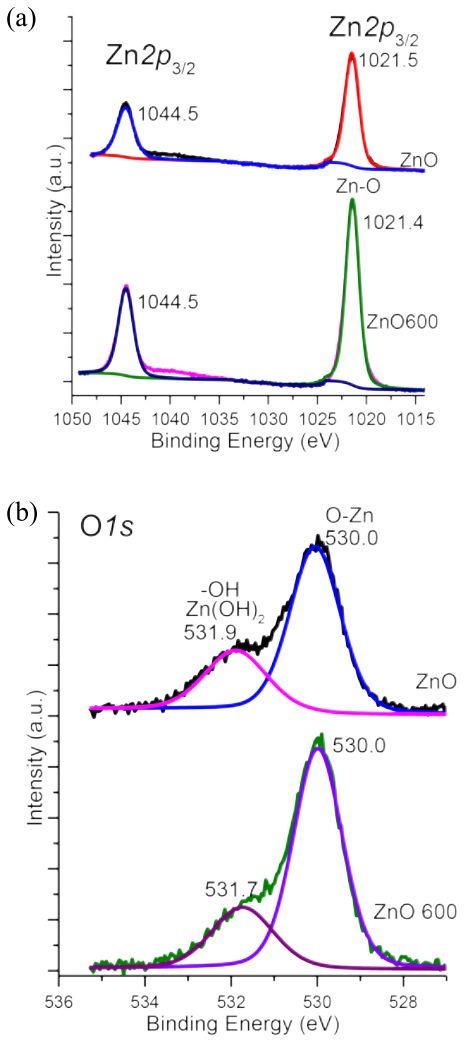

Fig. 8 XPS spectra in (a) $\mathrm{Zn} 2 p_{3 / 2}$ and (b) $\mathrm{O} 1 s$ of asreceived $\mathrm{ZnO}$ and milled-ZnO at $600 \mathrm{rpm}$.

Therefore, the peak at $530.0 \mathrm{eV}$ with slight shift should be attributed to oxygen of $\mathrm{Zn}-\mathrm{O}$ in $\mathrm{ZnO}$ lattice accompanying with small part of $\mathrm{Zn}-\mathrm{O}_{\text {vacancy }}$ at the inner surface, that is in accordance to the XPS spectra of $\mathrm{Zn} 2 p_{3 / 2}$ [28-30]. In addition, the $\mathrm{O} 1 \mathrm{~s}$ peak at 531.7 and $531.9 \mathrm{eV}$ normally associates to oxygen of surface adsorbed hydroxy group - $\mathrm{OH}$ and zinc hydroxide $\mathrm{Zn}(\mathrm{OH})_{2}$ [24,31-36]. However, there are no evidence of zinc hydroxide at $\mathrm{Zn} 2 p_{3 / 2}$ which should appear at around 1022.5$1023.4 \mathrm{eV}[27,37,38]$. This behavior suggests that the surface state is stable with insignificant influence by milling process.

\section{CONCLUSION}

High energy ball milling method was employed to reduce particle size of $\mathrm{ZnO}$ powder. Its size can be reduced from $530 \mathrm{~nm}$ to $240 \mathrm{~nm}$ with the milling speed of $600 \mathrm{rpm}$ for $10 \mathrm{~min}$. However, color change from white to pale yellow occurred as the powder was milled at higher speed beyond $400 \mathrm{~nm}$. Diffuse reflectance spectra of the milled sample in visible wavelength decreased significantly suggesting the existence of structural defects created during milling process that are responsible for this color change. PL spectra of the samples can qualitatively describe the increase of structural defects including zinc interstitial, oxygen interstitial, zinc vacancy and oxygen vacancy by ball milling process. Meanwhile, XPS results suggest that such defects are mostly located in $\mathrm{ZnO}$ lattice rather than at the surfaces.

Acknowledgements: Ravuri would like to thank King Mongkut's Institute of Technology Ladkrabang (KMITL), Thailand for offering as Visiting Professor under Academic Melting Pot Program. Photoluminescence spectroscopy supported by the Frontier Research Center, Vidyasirimedhi Institute of Science and Technology and XPS experiment supported by Synchrotron Light Research Institute (Public Organization) beamline 5.3 XPS (BL5.3: SUTNANOTEC-SLRI) are gratefully acknowledged.

\section{REFERENCES}

1. Lanje AS, Sharma SJ, Ningthoujam RS, Ahn JS, Pode RB (2013) Low temperature dielectric studies of zinc oxide ( $\mathrm{ZnO})$ nanoparticles prepared by precipitation method. Adv Powder Technol 24, 331-335.

2. Karimi M, Ezzati M, Akbari S, Lejbini MB (2013) ZnO microparticles, $\mathrm{ZnO}$ nanoparticles and $\mathrm{Zn}_{0.9} \mathrm{Cu}_{0.1} \mathrm{O}$ nanoparticles toward ethanol vapor sensing: A comparative study. Curr Appl Phys 13, 1758-1764.

3. Xie YP, He YP, Irwin PL, Jin T, Shi XM (2011) Antibacterial activity and mechanism of action of zinc oxide nanoparticles against Campylobacter jejuni. Appl Environ Microb 77, 2325-2331.

4. Boruah BD (2019) Zinc oxide ultraviolet photodetectors: rapid progress from conventional to self-powered photodetectors. Nanoscale $A d v \mathbf{1}$, 2059-2085.

5. Tudose IV, Suchea M (2016) ZnO for photocatalytic air purification applications. IOP Conf Ser Mater Sci Eng 133, ID 12040.

6. Kwon DK, Porte Y, Myoung JM (2018) Fabrication of $\mathrm{ZnO}$ nanorods $\mathrm{p}-\mathrm{n}$ homojunction light-emitting diodes using Ag film as self-doping source for p-type ZnO nanorods. $J$ Phys Chem C 122, 11993-12001.

7. Yu H, Wu Z, Dong Y, Huang C, Shi S, Zhang Y (2019) $\mathrm{ZnO}$ nanorod arrays modified with $\mathrm{Bi}_{2} \mathrm{~S}_{3}$ nanoparticles as cathode for efficient polymer solar cells. Org Electron 75, ID 105369.

8. Oliveira APA, Hochepied JF, Grillon F, Berger $\mathrm{MH}$ (2003) Controlled precipitation of zinc oxide particles at room temperature. Chem Mater 15, 3202-3207.

9. Widiyandari H, Umiati NAK, Herdianti RD (2018) Synthesis and photocatalytic property of Zinc Oxide $(\mathrm{ZnO})$ fine particle using flame spray pyrolysis method. J Phys Conf Ser 1025, ID 12004. 
10. Hasnidawani JN, Azlina HN, Norita H, Bonnia NN, Ratim S, Ali ES (2016) Synthesis of ZnO nanostructures using sol-gel method. Procedia Chem 19, 211-216.

11. Wirunmongkol T, O-Charoen N, Pavasupree S (2013) Simple hydrothermal preparation of zinc oxide powders using Thai autoclave unit. Enrgy Proced 34, 801-807.

12. Jayakumar OD, Salunke HG, Kadam RM, Mohapatra M, Yaswant G, Kulshreshtha SK (2006) Magnetism in Mn-doped $\mathrm{ZnO}$ nanoparticles prepared by a co-precipitation method. Nanotechnology 17 , 1278-1285.

13. Betancourt-Cantera JA, Sánchez-De Jesús F, BolarínMiró AM, Torres-Villaseñor G, Betancourt-Cantera LG (2019) Magnetic properties and crystal structure of elemental cobalt powder modified by high-energy ball milling. J Mater Res Technol 8, 4995-5003.

14. Lemine OM, Louly MA, Al-Ahmari AM (2010) Planetary milling parameters optimization for the production of ZnO nanocrystalline. Int J Phys Sci 5, 2721-2719.

15. Liu JH, Lv XJ, Li J, Zeng XP, Xu ZM, Zhang HL, Jiang LX (2016) Influence of parameters of high-energy ball milling on the synthesis and densification of magnesium aluminate spinel. Sci Sinter 48, 353-362.

16. Lv JP, Fang MH (2018) Photoluminescence study of interstitial oxygen defects in $\mathrm{ZnO}$ nanostructures. Mater Lett 218, 18-21.

17. Gomi M, Oohira N, Ozaki K, Koyano M (2003) Photoluminescent and structural properties of precipitated ZnO fine particles. Jpn J Appl Phys 42, 481-485.

18. Verma K, Chaudhary B, Kumar V, Sharma V, Kumar M (2017) Investigation of structural, morphological and optical properties of $\mathrm{Mg}$ : $\mathrm{ZnO}$ thin films prepared by sol-gel spin coating method. Vacuum 146, 524-529.

19. Willander M, Nur O, Sadaf JR, Qadir MI, Zaman S, Zainelabdin A, Bano N, Hussain I (2010) Luminescence from zinc oxide nanostructures and polymers and their hybrid devices. Materials (Basel) 3, 2643-2667.

20. Zeng H, Cai W, Hu J, Duan G, Liu Ps, Li Y (2006) Violet photoluminescence from shell layer of $\mathrm{Zn} / \mathrm{ZnO}$ core-shell nanoparticles induced by laser ablation. Appl Phys Lett 88, ID 171910.

21. Lyons JL, Varley JB, Steiauf D, Janotti A, Van de Walle CG (2017) First-principles characterization of nativedefect-related optical transitions in ZnO. J Appl Phys 122, ID 035704.

22. Erhart P, Albe K, Klein A (2006) First-principles study of intrinsic point defects in $\mathrm{ZnO}$ : Role of band structure, volume relaxation, and finite-size effects. Phys Rev B 73, ID 205203.

23. Rodnyi PA, Khodyuk IV (2011) Optical and luminescence properties of zinc oxide: a review. Opt Spectrosc 111, 776-785.
24. Alshammari AS, Chi LN, Chen XP, Bagabas A, Kramer D, Alromaeh A, Jiang Z (2015) Visible-light photocatalysis on C-doped $\mathrm{ZnO}$ derived from polymerassisted pyrolysis. RSC Adv 5, 27690-27698.

25. Pradhan D, Leung KT (2008) Controlled growth of two-dimensional and one-dimensional $\mathrm{ZnO}$ nanostructures on indium tin oxide coated glass by direct electrodeposition. Langmuir 24, 9707-9716.

26. Amor SB, Jacquet M, Fioux P, Nardin M (2009) XPS characterisation of plasma treated and zinc oxide coated PET. Appl Surf Sci 255, 5052-5061.

27. Liangyuan C, Zhiyong L, Shouli B, Kewei Z, Dianqing L, Aifan C, Liu CC (2010) Synthesis of 1-dimensional $\mathrm{ZnO}$ and its sensing property for CO. Sensor Actua $B$ Chem 143, 620-628.

28. Chen M, Wang Z, Han D, Gu F, Guo G (2011) Highsensitivity $\mathrm{NO}_{2}$ gas sensors based on flower-like and tube-like $\mathrm{ZnO}$ nanomaterials. Sensor Actua B Chem 157, 565-574.

29. Malik G, Mourya S, Jaiswal J, Chandra R (2019) Effect of annealing parameters on optoelectronic properties of highly ordered $\mathrm{ZnO}$ thin films. Mater Sci Semicond Proces 100, 200-213.

30. Pei Z, Ding L, Hu J, Weng S, Zheng Z, Huang M, Liu P (2013) Defect and its dominance in ZnO films: A new insight into the role of defect over photocatalytic activity. Appl Catal B Environ 142-143, 736-743.

31. Lu W, Gao S, Wang J (2008) One-Pot Synthesis of $\mathrm{Ag} / \mathrm{ZnO}$ self-assembled 3D hollow microspheres with enhanced photocatalytic performance. J Phys Chem C 112, 16792-16800.

32. Du Y, Zhang MS, Hong J, Shen Y, Chen Q, Yin Z (2003) Structural and optical properties of nanophase zinc oxide. Appl Phys A 76, 171-176.

33. Jing L, Xu Z, Shang J, Sun X, Cai W, Guo H (2002) The preparation and characterization of $\mathrm{ZnO}$ ultrafine particles. Mater Sci Eng A 332, 356-361.

34. Ramgir NS, Mulla IS, Pillai VK (2006) Micropencils and microhexagonal cones of ZnO. J Phys Chem B 110, 3995-4001.

35. Al-Gaashani R, Radiman S, Daud AR, Tabet N, AlDouri Y (2013) XPS and optical studies of different morphologies of $\mathrm{ZnO}$ nanostructures prepared by microwave methods. Ceram Int 39, 2283-2292.

36. Zemlyanov DY, Savinova E, Scheybal A, Doblhofer K, Schlögl R (1998) XPS observation of OH groups incorporated in an $\mathrm{Ag}(111)$ electrode. Surf Sci 418, 441-456.

37. Ahmed G, Hanif M, Mahmood K, Yao R, Ning H, jiao D, Wu M, Khan J et al (2018) Lattice defects of ZnO and hybrids with GO: Characterization, EPR and optoelectronic properties. AIP Adv 8, ID 025218.

38. Wang M, Jiang L, Kim EJ, Hahn SH (2015) Electronic structure and optical properties of $\mathrm{Zn}(\mathrm{OH})_{2}: \mathrm{LDA}+U$ calculations and intense yellow luminescence. RSC $A d v$ 5, 87496-87503. 